\title{
EFFECT OF VOLUME REDUCTION ON LUNG TRANSPLANT TIMING AND SELECTION FOR CHRONIC OBSTRUCTIVE PULMONARY DISEASE
}

Joseph E. Bavaria, MD

Alberto Pochettino, MD

Robert M. Kotloff, MD

Bruce R. Rosengard, MD

Peter M. Wahl, BA

J. R. Roberts, MD

Harold I. Palevsky, MD

Larry R. Kaiser, MD
Background: End-stage chronic obstructive pulmonary disease has traditionally been treated with lung transplantation. For 2 years, our lung transplantation program has placed patients with appropriate criteria for lung transplantation and volume reduction into a prospective management algorithm. These patients are offered the lung volume reduction option as a "bridge" to "extend" the eventual time to transplantation. We examine the results of this pilot program. Methods: From October 11, 1993, to April 17, 1997, 31 patients were evaluated for lung transplantation who also had physiologic criteria for volume reduction (forced expiratory volume in 1 second $\leq 25 \%$; residual volume $>200 \%$; significant ventilation/perfusion heterogeneity). All patients completed 6 weeks of pulmonary rehabilitation and then had baseline pulmonary function and 6-minute walk tests. These patients were then offered volume reduction as a "bridge" and were simultaneously listed for transplantation. Postoperatively, these 31 patients were then divided into two groups: Those with satisfactory results at 4 to 6 months after volume reduction and those with unsatisfactory results. Volume reduction was performed through a video thoracic approach in $87 \%$ of the patients and bilateral median sternotomy in the remaining $13 \%$. The condition of the patients was monitored after the operation with repeated pulmonary function tests and 6-minute walk tests at 3-month intervals. Results: Twenty-four of 31 patients $(77.4 \%$ ) had primary success (at 4 to 6 months) results after lung volume reduction and 7 patients $(22.6 \%)$ had primary failure, including 1 patient who died in the perioperative period (3.2\%). Four patients $(16.7 \%)$ from the primary success cohort had significant deterioration in their pulmonary function during intermediateterm follow-up and were then reconsidered for lung transplantation. Two of them have subsequently undergone transplantation with good postoperative pulmonary function results. Interestingly, three patients had $\alpha_{1}$ antitrypsin deficiency; two had a poor outcome of lung volume reduction and primary failure. Conclusions: Lung volume reduction in these patients is safe. Seventy-seven percent of otherwise suitable candidates for lung transplantation achieved initial good results from volume reduction and were deactivated from the list (placed on status 7). Most patients entering our prospective management algorithm have either significantly delayed or completely avoided lung transplantation after volume reduction. Lung volume reduction has substantially affected the practice, timing, and selection of patients for lung transplantation. Our waiting list now has a
From the Departments of Cardiothoracic Surgery and Pulmonary Medicine, University of Pennsylvania Medical Center, Philadelphia, Pa.

Read at the Seventy-seventh Annual Meeting of The American Association for Thoracic Surgery, Washington, D.C., May 4-7, 1997.

Received for publication May 7, 1997; revisions requested July 7, 1997; revisions received Sept. 12, 1997; accepted for publication Sept 15, 1997.
Address for reprints: Joseph E. Bavaria, MD, Director, Lung Transplant Program, Department of Surgery, 4 Silverstein, Hospital of the University of Pennsylvania, 3400 Spruce St., Philadelphia, PA 19104.

J Thorac Cardiovasc Surg 1998;115:9-18

Copyright (C) 1998 by Mosby, Inc.

$0022-5223 / 98 \$ 5.00+0 \quad \mathbf{1 2 / 6 / 8 6 1 9 0}$ 
reduced percentage of patients with a diagnosis of chronic obstructive pulmonary disease compared with 3 years ago. Our experience suggests that lung volume reduction may be limited as a "bridge" in $\alpha_{1}$-antitrypsin deficiency. (J Thorac Cardiovasc Surg 1998;115:9-18)

$\mathrm{T}_{\mathrm{n}}^{\mathrm{t}}$ he surgical treatment of chronic obstructive pulmonary disease (COPD) has historically been quite a challenge. The initial attempt at lung volume reduction (LVR) surgery for emphysema was made by Brantigan and colleagues ${ }^{1}$ with little success. However, giant bullous disease and other bullous conditions have been treated surgically with success for quite some time., 3 In the early 1980s, lung transplantation was developed for end-stage COPD, which initially included both heart-lung and doublelung transplant procedures. ${ }^{4}$ The transplantation of two lungs was thought to be necessary to alleviate any severe ventilation/perfusion (V/Q) mismatch or potential hyperinflationary mediastinal complications that were theoretically possible with single lung transplantation (SLT). ${ }^{5}$ In 1989, Mal and associates, ${ }^{6}$ as well as Calhoun and coworkers, ${ }^{7}$ reported early clinical series of isolated SLT for COPD.

Bilateral sequential lung transplantation for COPD has also been gaining favor more recently. ${ }^{8-10}$ Concurrent to the development of various lung transplantation procedures designed to treat end-stage COPD, other surgeons were investigating the use of laser or other resection techniques in patients with emphysema. ${ }^{11,12}$ In 1995, Cooper and colleagues $^{13}$ presented a landmark series of patients undergoing bilateral LVR for emphysema with median sternotomy with excellent short-term clinical results. After this series was published, other surgeons reported good clinical results with both unilateral and bilateral LVR by use of the newly emerging video thoracic technology. ${ }^{14,15}$

By 1994, it became clear to our lung transplantation team that some patients referred with end-stage COPD were candidates for both LVR and lung transplantation. The emergence of LVR as a treatment modality for COPD and our encouraging results in more than 150 patients over the past 3 years ${ }^{16}$ have allowed us to identify a subgroup of patients with COPD who may benefit from LVR either in lieu of lung transplantation or as a bridge to transplantation. Our desire to develop alternatives to lung transplantation has been further fueled by the continued scarcity of available donor organs. With these two effective treatment modalities avail- able for end-stage COPD, our lung transplant program developed a strategy for patients with appropriate criteria for both lung transplantation and LVR and placed them into a prospective management algorithm. Patients who were candidates for both procedures were offered LVR as a preliminary "bridge" to lung transplantation. It was completely unclear to us, when designing this prospective algorithm, whether LVR would be effective in these patients with a low forced expiratory volume in 1 second $\left(\mathrm{FEV}_{1} ; \leq 25 \%\right)$, especially in those patients with an $\mathrm{FEV}_{1}<19 \%$, because scant patient data were available on this particular cohort. Additionally, it was unclear how many patients would obtain sufficient benefit to allow the LVR procedure to completely replace lung transplantation or whether a successful LVR would simply act to "prolong" the eventual time to transplantation. This report analyzes the results of our pilot program involving 31 patients who were prospectively placed in a surgical management scheme consisting of (1) LVR, (2) simultaneous listing for lung transplantation, and (3) subsequent close follow-up at 4 to 6 months, at which time a decision was made either to keep the patient on the list (primary failure) or to place him or her on status 7 (primary success).

\section{Patients and methods}

Source of referred patients. Four hundred fifty-six patients between October 30, 1991, and April 11, 1997, were referred to the University of Pennsylvania Lung transplant program for the evaluation of end-stage lung disease. Of these patients, $225(49.3 \%)$ had with end-stage COPD. This diagnosis category includes end-stage emphysema and $\alpha_{1}$ antitrypsin deficiency (A-1). Of these 225 evaluated patients, $35(15.6 \%)$ were excluded for comorbid conditions. Twenty $(8.9 \%)$ patients did not fit the criteria for lung transplantation but were candidates for LVR. Beginning in October 1993, we recognized that some patients who would be good candidates for lung transplantation would also be considered appropriate candidates for LVR. Since October 1993, 31 $(13.3 \%)$ patients were candidates for both LVR and lung transplantation. This represents the core group of patients studied in this series. The remaining 139 patients (61.8\%) were referred directly for lung transplantation and were not considered for LVR.

Lung transplantation inclusion criteria. Lung transplantation inclusion criteria for patients with end-stage 
COPD include (1) an $\mathrm{FEV}_{1}<30 \%$ of predicted (by 1993 this was changed to an $\mathrm{FEV}_{1}<25 \%$ predicted), (2) age $<$ 65 , (3) no significant comorbidities and other organ system dysfunction, (4) a 6-minute walk test (6MWT) distance $\tau 600$ feet, (5) body weight not under or exceeding $25 \%$ of predicted ideal range, (6) no history of substance abuse, (7) no active or recent smoking, and (8) adequate social support and stable psychosocial setting.

Inclusion criteria for LVR. During the early phases of our program, the best indications for LVR were not completely defined. As our experience grew, however, it has become clear that inclusion criteria for LVR include residual volume (RV) $\tau$ than $200 \%$, pulmonary artery systolic pressure $<50 \mathrm{~mm} \mathrm{Hg}, 6 \mathrm{MWT} \tau 600 \mathrm{feet}$, and a quantitative V/Q scan that reveals significant "heterogeneity." The most optimal V/Q scan for LVR reveals bilateral apical flow distributions $<10 \%$ of the total. Additionally, we excluded patients with a carbon dioxide tension $>50 \mathrm{~mm} \mathrm{Hg}$. As in the lung transplant program, anyone with active smoking was contraindicated for LVR. Significant bronchospasm or an asthmatic component to end-stage COPD was considered a contraindication to operation. Identical weight restrictions as defined in the lung transplant program exclusion criteria also applied to LVR. All patients eligible for LVR were required to undergo at least 6 weeks of formal pulmonary rehabilitation. Repeat pulmonary function tests were then obtained after pulmonary rehabilitation and before the LVR procedure.

Patient characteristics. Our pilot study group consists of the 31 patients considered good candidates for either procedure. A summary of the demographics for these 31 patients can be seen in Table I.

Decision making/pathway algorithm. Once patients were considered candidates for both LVR and lung transplantation, the following prospective algorithm was followed. All patients were simultaneously listed for lung transplantation while LVR was scheduled. After LVR, patients were evaluated at 3 and 6 months after the operation. Repeat pulmonary function studies and 6MWTs were performed. At 6 months, if the patients had a sustained and satisfactory result (primary success) from their LVR operation, they were then removed from the list (placed on status 7). Those patients who had an unsatisfactory outcome after LVR were then kept on the lung transplant list and the LVR was considered a primary failure. Patients placed on status 7 were continuously evaluated by the lung transplant program for any signs of future progressive decline in their pulmonary function (late failure). For some of these patients, it is probable that LVR will act to delay or postpone, but not to eliminate, the need for lung transplantation. It should be noted that our average time spent on the waiting list before lung transplantation is currently approximately 18 months.

Surgical procedures. LVR was performed by a videoassisted thoracic approach in $87 \%$ of the patients and by a bilateral median sternotomy in $13 \%$. Twelve patients $(39 \%)$ in this study $(n=31)$ had $\mathrm{FEV}_{1} \leq 19 \%$ predicted. It is our bias that patients with poor $\mathrm{FEV}_{1}$ have higher perioperative mobidity and mortality. ${ }^{17}$ Therefore we try to avoid bilateral manipulation of the lungs in this high-
Table I. Patient demographics

\begin{tabular}{lcc}
\hline \multicolumn{1}{c}{ Patient demographics $(N=31)$} & Mean & Standard deviation \\
\hline Age $(\mathrm{yr})$ & 53.4 & 6.3 \\
$\%$ Male $^{*}$ & 34.5 & - \\
Preoperative FEV $_{1}$ (\% predicted) $\dagger$ & 23.3 & 4.8 \\
Preoperative RV (\% predicted) & 258.0 & 36.2 \\
Preoperative 6MWT (ft) & 962 & 326 \\
PAS (mm Hg) & 33.5 & 5.9 \\
PcO $^{2}$ (torr) & 41.4 & 5.6 \\
\% IBW & 109.9 & 21.3 \\
V/Q scan $\ddagger$ & & \\
Upper left third $(\%)(n=28)$ & 7.2 & 3.7 \\
Upper right third $(\%)(n=28)$ & 5.1 & 3.0 \\
Lower left third $(\%)(n=3)$ & 4.9 & 1.2 \\
Lower right third $(\%)(n=3)$ & 6.3 & 1.3
\end{tabular}

$F E V_{l}$, Forced expiratory volume in $1 \mathrm{sec} ; R V$, residual volume; $6 M W T$ distance covered during a 6-minute walk test; $P A S$, pulmonary artery systolic pressure; $\mathrm{PCO}_{2}$, partial pressure of arterial carbon dioxide; \%IBW, percent of ideal body weight.

*All variables expressed as the mean except for \% Male.

$\dagger$ Twelve of 31 patients had $\mathrm{FEV}_{1} \leq 19 \%$ of predicted.

$\ddagger \mathrm{V} / \mathrm{Q}$ scan results were quantitated by dividing lack lung perfusion unit into upper third, middle third, and lower third. Twenty-eight patients were "classic" with apical "heterogeneity" on V/Q scan.

risk group and use bilateral video sequential LVR as the procedure of choice for patients with $\mathrm{FEV}_{1} \leq 19 \%$ predicted. Seventeen patients $(55 \%)$ with $\mathrm{FEV}_{1} \geq 20 \%$ predicted had bilateral LVR. Four of these patients had median sternotomy, and the remaining 13 had a bilateral video-assisted thoracic approach. The 12 patients with $\mathrm{FEV}_{1} \leq 19 \%$ predicted were offered the bilateral sequential video-assisted thoracic approach. Five of these patients completed the second side, but the remaining seven patients had such a satisfactory result that they either refused or postponed completion of the contralateral lung, confirming previous reports regarding the efficacy of unilateral LVR. ${ }^{14,15}$ Two patients had planned unilateral LVR as a result of previous thoracotomy and significant $\mathrm{V} / \mathrm{Q}$ mismatch.

LVR operative technique. All patients were placed into a supine position. Those who underwent median sternotomy had a standard procedure as described elsewhere. ${ }^{13,16}$ The bilateral video thoracic procedure was performed with the patient in the supine position with a beanbag strategically placed so that the table could roll to 30 degrees, exposing an anterolateral position on each side. The arms were placed above the face in a flexed position as originally described for bilateral sequential lung transplantation. ${ }^{8}$ Epidural anesthesia was used in all patients, as well as double-lumen endotracheal tubes. Hypoperfused areas of lung, defined by V/Q scanning, allowed us to target areas of lung for resection. Approximately $20 \%$ of the lung tissue from each lung was removed as wedge resections. Those patients operated on by use of a median sternotomy also had bovine pericardial buttressing of the pulmonary staple lines.

Statistical analysis. All means are expressed as the mean \pm the standard deviation. Two-tailed $t$ tests were used to compare the means of normally distributed vari- 


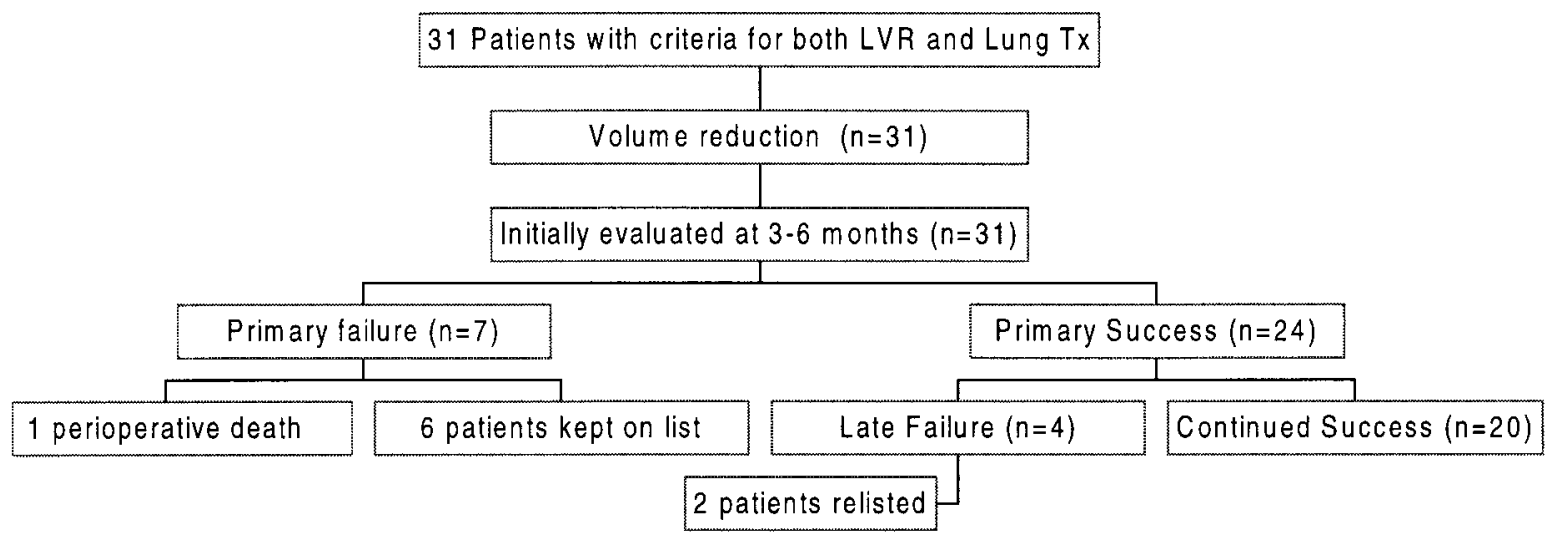

Fig. 1. Results/patient flow from prospective LVR/transplant algorithm. Note: three patients underwent transplantation; two of four late failures did not meet ongoing criteria for transplant; two of six patients with primary failure were subsequently deactivated from the list for noncompliance.

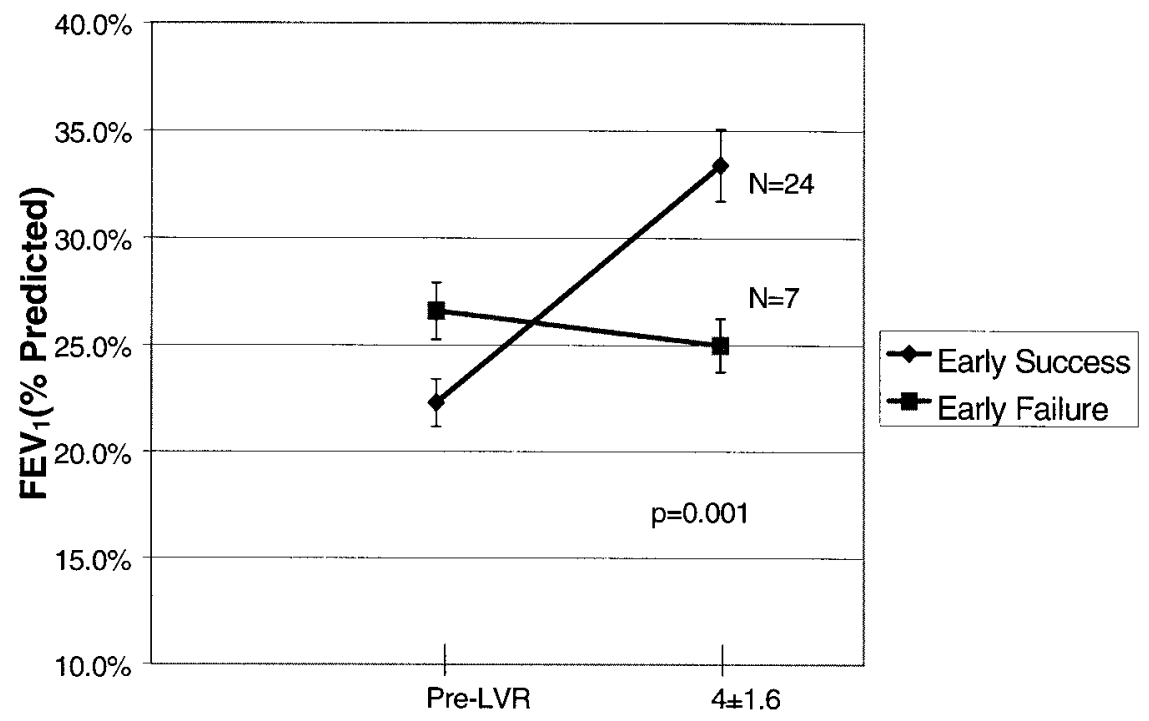

\section{Time (months)}

Fig. 2. Initial $\mathrm{FEV}_{1}$ response $(n=28)$ : primary successes versus primary failures. This graph shows the results in $\mathrm{FEV}_{1}$ after LVR of the primary success group and primary failure group. Patients with primary successes were then placed on status 7. Those with primary failure were kept on the transplant list. $p$ Value shown refers to the difference in percent change in $\mathrm{FEV}_{1}$.

ables in independent groups. Statistical significance was considered to be achieved where $p$ is $<0.05$.

\section{Results}

Initial (primary) results. All 31 patients with acceptable criteria for both LVR and lung transplantation were entered into the prospective algorithm (Fig. 1). LVR was performed on all 31 patients, and they were evaluated at 4 to 6 months.
There were 24 primary successes (77\%), and 7 primary failures (23\%) (Fig. 2). Patients in the primary success group were placed on status 7 ( $n=$ 24 ), and those with primary failure were kept on the transplant list and accrued time.

Perioperative mortality. One patient (1/31, $2.9 \%$ ) died during the perioperative period. This was a patient with A-1 disease who underwent bilateral LVR by use of a median sternotomy. This 


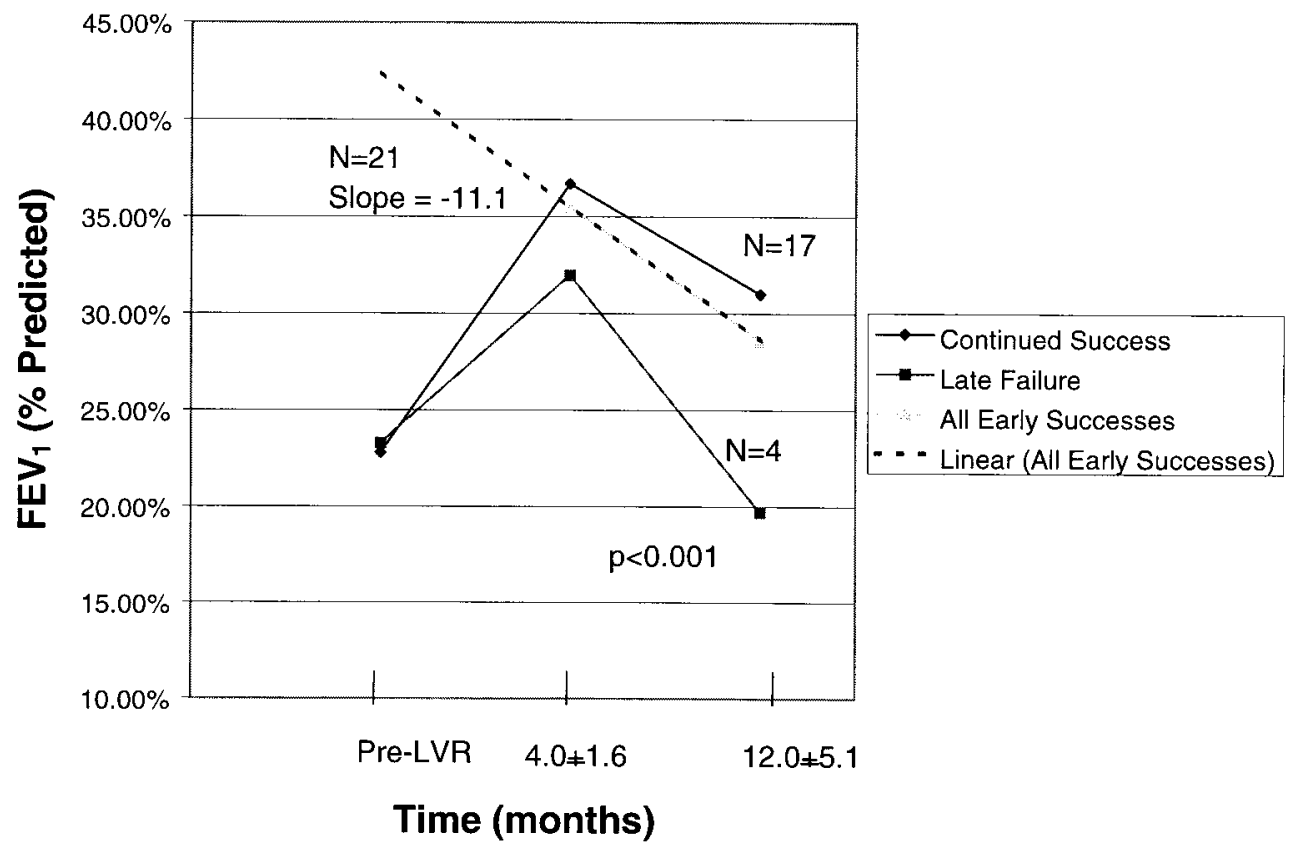

Fig. 3. Intermediate-term pulmonary function decline in primary success cohort. This graph demonstrates the decline in pulmonary function over a 12-month period in patients with a primary LVR success. Four of 21 primary successes were subsequent late failures. Note that these four patients (late failures) had rapid early declines in $\mathrm{FEV}_{1} . p$ Value shown represents the difference in rate of decline between the continued successes and the late failures, from the point at which peak $\mathrm{FEV}_{1}$ was reached (mean time $=4.0$ months) until most recent testing (mean time $=12.0$ months). Two of four with late failure were put back on the list and underwent transplantation; the remaining two (mean $=26$ months after LVR) were subsequently considered poor candidates for transplantation because of age (both 65 years old at present), recently acquired heart failure, and worsening osteoporosis.

Table II. Functional outcomes of initial past LVR review

\begin{tabular}{|c|c|c|c|c|c|c|}
\hline Group & Pre FEV & Post FEV $V_{1}$ & Pre $R V$ & Post RV & Pre $6 M W T$ & $\begin{array}{c}\text { Post } \\
6 M W T\end{array}$ \\
\hline Primary success $(n=24)$ & $23 \%$ & $\begin{array}{c}35 \% \\
p=0.0002\end{array}$ & $266 \%$ & $\begin{array}{c}205 \% \\
p=.00001\end{array}$ & $848 \mathrm{ft}$ & $\begin{array}{c}1287 \mathrm{ft} \\
p=.00002\end{array}$ \\
\hline Primary failure $(n=7)$ & $26.5 \%$ & $\begin{array}{r}25 \% \\
p=\mathrm{NS}\end{array}$ & $228 \%$ & $\begin{array}{l}232 \% \\
p=\mathrm{NS}\end{array}$ & $1119 \mathrm{ft}$ & $\begin{array}{l}1212 \mathrm{ft} \\
p=\mathrm{NS}\end{array}$ \\
\hline
\end{tabular}

$L V R$, Lung volume reduction; $F E V_{1}$, forced expiratory volume in 1 second; $R V$, residual volume; $6 M W T$, 6-minute walk test distance. $p$ values shown represent results of two-tailed $t$ tests of paired data.

patient also had an extensive history of alcohol abuse and had delirium tremors while in the regular inpatient department on postoperative day 3. Adult respiratory distress syndrome developed, with eventual respiratory failure. No other patient required tracheostomy or postopertive mechanical ventilation.

Functional results. Pulmonary function testing and 6MWT results for the primary success $(n=24)$ and primary failure $(n=7)$ groups are shown in Table II.
Examination of primary failures. Two patients in the primary failure group had A-1 disease. At 6 months' follow-up, their pulmonary function test results were not significantly improved. One patient, who had a left unilateral LVR, had a V/Q scan that showed $71 \%$ of flow to the right side and $29 \%$ of flow to the left side. On further examination, the patient showed evidence of a unilateral "vanishing lung syndrome" and was probably a poor candidate for LVR. A fourth patient had a very poor preoperative carbon monoxide diffusing capacity (DLCO) 


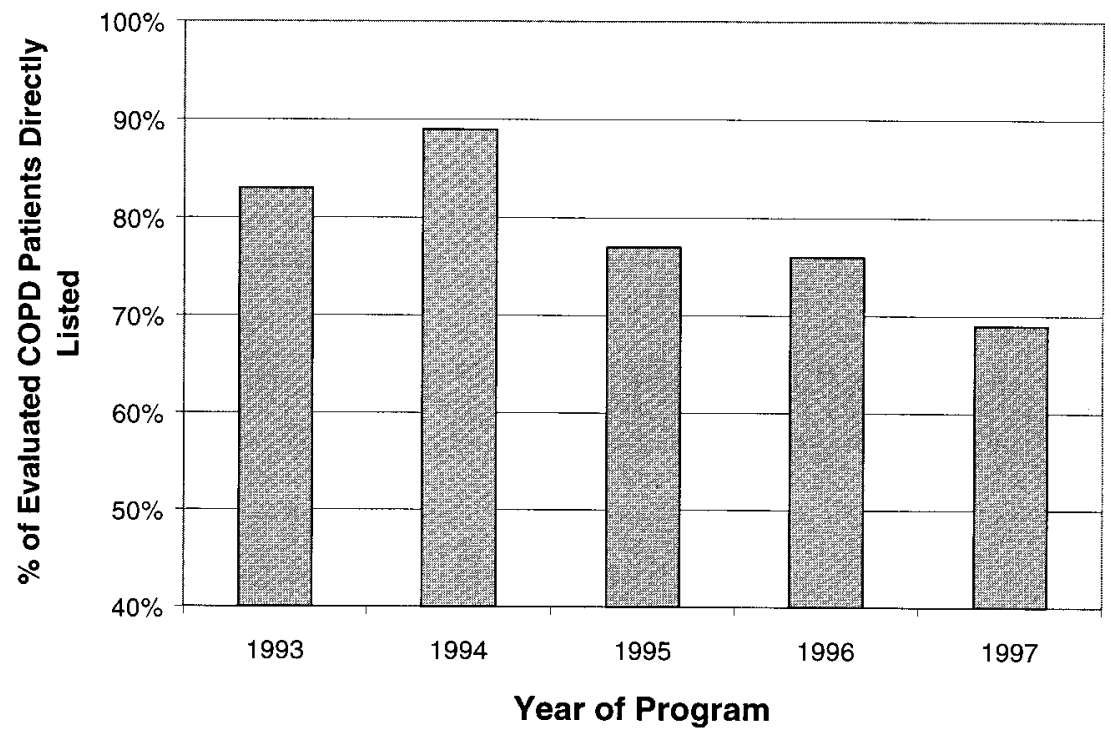

Fig. 4. Percentage of evaluated patients with COPD subsequently listed for lung transplantation only. Excludes both (1) patients with a standard contraindication to transplant and (2) those placed on the "prospective" LVR management algorithm. Note: Lung transplant program evaluations initiated in July 1991.

Table III. Results for patients with initial LVR then subsequent single lung transplant $(n=3)$

\begin{tabular}{lccc}
\hline & \multicolumn{3}{c}{ Best } \\
& Pre-LVR & post-LVRR & posttransplant \\
\hline FEV $_{1}(\%$ predicted $)$ & $25.0 \pm 7.0$ & $27.3 \pm 6.7$ & $62.7 \pm 21.6$ \\
RV (\% predicted) & $243.3 \pm 39.7$ & $179.0 \pm 64.2$ & $112.5 \pm 58.7$ \\
\hline
\end{tabular}

$L V R$, Lung volume reduction; $F E B_{1}$, forced expiratory volume in 1 second; $R V$, residual volume. All values expressed as mean \pm standard deviation Mean time from date of LVR to date of lung transplant is $14.0 \pm 8.5$ months.

value $(7=25 \%$ of predicted $)$. He had good $\mathrm{FEV}_{1}$ and RV improvement after LVR but had a significant increase in oxygen requirements. This was even more dramatic during exercise. For this reason, we believed that this was an LVR failure and kept him on the transplant list. The remaining two patients in whom LVR was considered a primary failure had "classic" apical disease and we can find no specific reason for their poor initial LVR results.

Effect of strict inclusion criteria. Further analysis of the results reveals that patients with "classic" disease, defined as a V/Q scan showing $<10 \%$ flow to each upper-third lung field (apical emphysematous disease) and RV $>225 \%$, did quite well. This excludes patients with previous thoracotomy, very low DLCO, A-1, and significant V/Q scan flow imbalance to either lung. In patients with this strict classification of apical emphysematous disease the primary success rate was $94 \%$.
Examination of late failures. Four of the 24 patients in whom LVR was a primary success $(16.7 \%)$ eventually declined to the point at which their pulmonary function was very poor, requiring reevaluation and relisting for transplantation. The remaining 20 patients continue to have a clinically satisfactory result. Eleven of these continued successes $(55 \%)$ had long-term data (mean follow-up time of 10 months) that permitted us to compare the slope of pulmonary function decline relative to the four late failures. A significantly different slope of pulmonary function decline was found between these two groups (Fig. 3). Three patients who are doing well after LVR do not have 6-month follow-up at this time and therefore were excluded from this longer term analysis, although at present they are in the primary success group. The remaining six have not had satisfactory objective follow-up past 1 year. Two of these patients moved away from the geographic area. The other four patients feel good subjectively at this time and their results are still considered a continued success. Two of the four experiencing late failure were reevaluated for lung transplantation, put on the list again, and had successful transplantation without difficulty. The remaining two patients were put on the list again and subsequently removed because of heart failure and osteoporosis; both patients were 65 years of age at the time. 


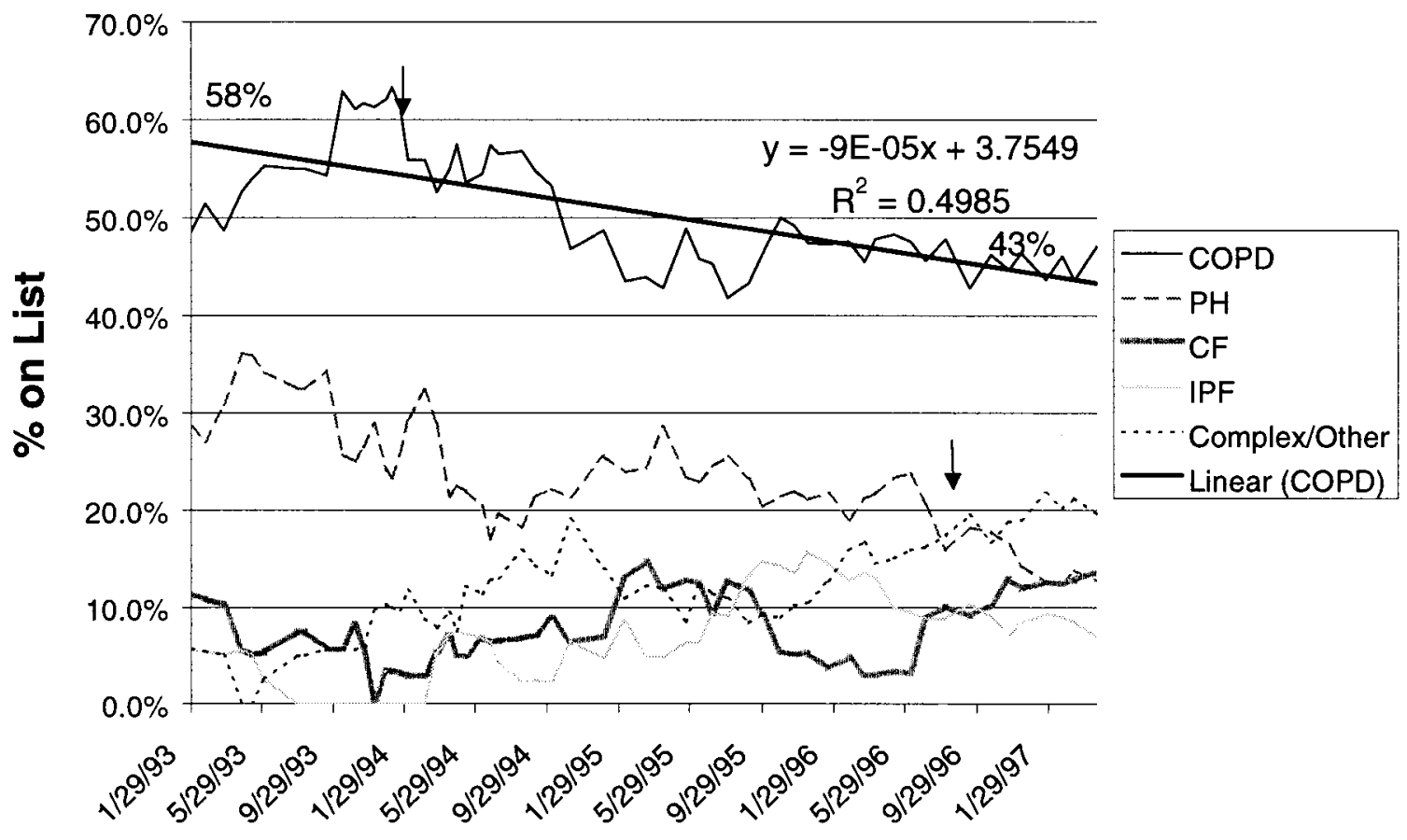

\section{List Date}

Fig. 5. Changes in composition of the lung transplant list over time. Note decreasing percentage of COPD and pulmonary hypertension diagnoses and the increased percentages of interstitial pulmonary fibrosis, cystic fibrosis, and other complex end-stage lung disease. The first arrow shows when LVR Prospective Management Algorithm was initiated; the second arrow shows when in-house IV Prostacyclin Protocol began for treatment of patients with pulmonary hypertension. NOTE: percent of patients with COPD on the list would have been even lower if medical treatment of primary pulmonary hypertension was not so successful. $P H$, Primary pulmonary hypertension and Eisenmenger's syndromes; IPF, interstitial pulmonary fibrosis; $C F$, cystic fibrosis. Complex/Other, pulmonary alveolar microlithiasis, bronchiolitis obliterans, sarcoidosis, lymphangioleiomyomatosis, scleroderma, bronchiectasis, Noonan's syndrome, chronic pulmonary embolism, pulmonary venous obstructive disease, asthma, Kartagener's syndrome, berylliosis, chronic granulomatous disease, and silicosis.

SLT. Three patients have undergone transplantation as of the writing of this article after LVR. SLT was performed without substantial added difficulty after LVR. The functional "timeline" for these patients is shown in Table III. Three post-LVR patients currently remain on the transplant list awaiting SLT.

Effect of prospective management algorithm on transplant list composition. Fig. 4 shows the gradual decrease in the percent of evaluated patients with COPD who are directly listed. This excludes both patients with a standard contraindication to transplantation and those placed on the "prospective LVR management algorithm." Fig. 5 shows the changes in composition of the lung transplant list by diagnosis over time. The percentage of patients with a diagnosis of COPD on the transplant list has been decreasing since the inception of this program, as noted by the upper arrow on Fig. 4. In addition, the percentage of pulmonary hypertension diagnoses on our transplant list has decreased and idiopathic pulmonary fibrosis, cystic fibrosis, and all other complex diagnoses have corrrespondingly increased.

\section{Discussion}

At present, our institution has performed 155 lung transplant and $166 \mathrm{LVR}$ procedures. It became clear to us, in late 1993, that some patients would meet the criteria for both (or either) procedures. A strategy to properly manage these patients was needed. We initiated a prospective management algorithm for patients who were candidates for both 
surgical treatments for emphysema and A-1 (COPD). The analysis of this pilot study focuses on 31 patients who were identified prospectively to meet the criteria for both LVR and transplantation.

The prospective LVR/transplant management algorithm consisted of 6 weeks of pulmonary rehabilitation with simultaneous listing for transplantation. LVR was scheduled and completed after 6 weeks of pulmonary rehabilitation. Four to 6 months after LVR, a complete evaluation was performed, including $\mathrm{FEV}_{1}, \mathrm{RV}$, and $6 \mathrm{MWT}$ tests. At that time, the treatments were declared either a primary success or a primary failure. Treatment of $77 \%$ of the patients was a primary successes and treatment of $23 \%$ was considered a primary failure. The primary failure group was kept on the transplant list, and the primary success group was considered status 7 and followed up by the lung transplant team. Of the patients with initially satisfactory results, $16.7 \%$ then had pulmonary function decline and required reevaluation and potential relisting for transplantation.

As reported by other authors, ${ }^{15,16,18}$ the mean improvement in $\mathrm{FEV}_{1}$ was approximately $50 \%$ in our primary success cohort. Further analysis of the data suggests that if we are more rigorous in our selection criteria and exclude patients with previous thoracotomy, low DLCO, and A-1, we may be able to improve the frequency of our primary successes. These data would corroborate the emerging consensus that patients with "classic" apical emphysematous disease with high RVs and significant V/Q heterogeneity are the best candidates for this procedure. ${ }^{17}$ Interestingly, despite our data showing these patients with classic apical disease performing better initially, some patients still had significant late decline in pulmonary function.

In this pilot program, we identified a significant percentage of patients in whom the need for transplantation was delayed or even eliminated. The LVR procedure is safe in this group of very severely compromised patients with COPD. Of our patient population $39 \%$ had $\mathrm{FEV}_{1} \mathrm{~s}$ of $\leq 19 \%$ of predicted, and our overall mortality was $3.2 \%$. On the other hand, in $23 \%$ of the patients who entered our prospective algorithm LVR was a primary failures, with an additional four patients having substantial decline and late failure. Overall, this corresponds to $32 \%$ of the entire prospective cohort potentially requiring lung transplantation for both initial and late LVR failure. This evidence amplifies the necessity for continued surveillance of these critically ill patients on the status 7 transplant list.
As noted by Dusmet and colleagues,${ }^{19}$ SLT after LVR was technically successful in three patients. Results of lung transplantation were comparable to previously published improvements in pulmonary function after SLT. 6, 9, 20 Two of three patients with A-1 had poor initial results. The third patient had relatively minor improvements in $\mathrm{FEV}_{1}$ but does have a significant subjective improvement and is therefore still considered to have continued success at this time. These results suggest that patients with A-1 disease may not be proper candidates for this prospective management algorithm using LVR as a means to extend eventual lung transplantation. Other reports have also alluded to the fact that LVR for patients with A-1 disease may not lead to uniformly satisfactory results compared with classic apical emphysematous disease. ${ }^{16,21,22}$

The availability of LVR has made an impact on our transplant list composition and our end-stage COPD transplant evaluation process. At present, we list a smaller percentage of patients with COPD than we did previously. The percentage of COPD patients directly listed after initial evaluation peaked in 1994. Moreover, our lung transplant list composition has a lower percentage of patients with COPD compared with previous years. The reasons for this are complex and may have to do with a combination of multiple factors: (1) the initiation of LVR, (2) the addition of an outpatient intravenous prostacyclin protocol for pulmonary hypertension, (3) the fact that our lung transplant program has become more experienced since its inception in July 1991, and (4) the percentage of complex cases and referrals such as cystic fibrosis, sarcoidosis, and interstitial pulmonary fibrosis have increased.

\section{REFERENCES}

1. Brantigan OC, Mueller E, Kress MB. A surgical approach to pulmonary emphyesema. Am Rev Respir Dis 1959;80:194202.

2. Vejlsted H, Halker EE. Surgical improvement of patients with pulmonary insufficiency due to localized bullous emphysema or giant cysts. Thorac Cardiovasc Surg 1985;33:335-7.

3. Connolly JE, Wilson A. The current status of surgery for bullous emphysema. J Thorac Cardiovasc Surg 1989;97:35161.

4. Cooper JD, Patterson GA, Grossman R, Maurer J. Doublelung transplant for advanced chronic obstructive lung disease. Am Rev Respir Dis 1989;139:303-7.

5. Veith FJ, Koerner SK. Problems in the management of human lung transplant patients. Vasc Surg 1974;8:273-82.

6. Mal H, Andreassian B, Pamela F, et al. Unilateral lung transplantation in end-stage pulmonary emphysema. Am Rev Respir Dis 1989;140:797-802.

7. Calhoun JH, Grove FL, Gibbons WJ, et al. Single lung 
transplantation: alternative indications and techniques. J Thorac Cardiovasc Surg 1991;101:816-25.

8. Kaiser LR, Pasque MK, Trulock EP, et al. Bilateral sequential lung transplant: the procedure of choice for double lung replacement. Ann Thorac Surg 1991;52:438-46.

9. Sundaresan RS, Shiraishi Y, Trulock EP, et al. Single or bilateral lung transplantation for emphysema? J Thorac Cardiovasc Surg 1996;112:1485-95.

10. Bavaria JE, Kotloff R, Palevsky H, et al. Bilateral versus single lung transplantation for chronic obstructive pulmonary disease. J Thorac Cardiovasc Surg 1997;113:520-8.

11. Lewis RJ, Caccavale RJ, Sisler GE. VATS-argon beam coagulator treatment of diffuse end-stage bilateral bullous disease of the lung. Ann Thorac Surg 1993;55:1394-9.

12. Wakabayashi A, Brenner A, Kayaleh R, et al. Thoracoscopic carbon dioxide laser treatment of bullous emphysema. Lancet 1991;337:881-3.

13. Cooper JD, Trulock EP, Triantafillou AN, et al. Bilateral pneumectomy (volume reduction) for chronic obstructive pulmonary disease. J Thorac Cardiovasc Surg 1995;109:10619.

14. Keenan RJ, Landreneau RJ, Sciurba FC, et al. Unilateral thoracoscopic surgical approach for diffuse emphysema. J Thorac Cardiovasc Surg 1996;111:308-16.

15. McKenna RJ Jr, Brenner M, Fischel RJ, Gelb AF. Should lung volume reduction for emphysema be unilateral or bilateral? J Thorac Cardiovasc Surg 1996;112:1331-9.

16. Kotloff RM, Tino G, Bavaria JE, et al. Bilateral lung volume reduction surgery for advanced emphysema: a comparison of median sternotomy and thoracoscopic approaches. Chest 1996;110:1399-406.

17. McKenna RJ, Fischel RJ, Brenner M, Gelb A. Patient selection criteria for lung volume reduction surgery. Abstract presented at the Twenty-second Annual Meeting of the Western Thoracic Surgical Association, Wailea, Maui, Hawaii, June 26-29, 1996.

18. Cooper JD, Patterson GA, Sundaresan RS, et al. Results of 150 consecutive bilateral lung volume reduction procedures in patients with severe emphysema. J Thorac Cardiovasc Surg 1996;112:1319-30.

19. Dusmet M, Winton TL, Kesten S, Maurer J. Previous intrapleural procedures do not adversely affect lung transplantation. J Heart Lung Transplant 1996;15:249-54.

20. Marinelli WA, Hertz MI, Shumway SJ, et al. Single lung transplantation for severe emphysema. J Heart Lung Transplant 1992;11:577-83.

21. Browne RJ, Mannino DM III, Khoury MJ. Alpha ${ }_{1}$-antitrypsin deficiency deaths in the United States from 1979-1991: an analysis using multiple-cause mortality data. Chest 1996;110; 78-83.

22. Barker AF. Alpha-1 antitrypsin deficiency-related emphysema. J Am Board Fam Pract 1992;5:489-92.

\section{Discussion}

Dr. G. Alexander Patterson (St. Louis, Mo.). Dr. Bavaria and his colleagues have brought to our attention a very important problem in the evaluation of emphysema patients for surgical management.

At first glance, it may seem that a selection dilemma exists between LVR and transplantation for patients with advanced end-stage emphysema. In fact, there really are very few patients for whom either option is suitable; indeed, in the Pennsylvania experience, only 31 of 225 evaluated patients were thought suitable for either procedure. These patients were listed for transplant before LVR. That is a sensible option given the expected 18 months' pretransplant waiting time in their program.

Although three quarters of these patients did derive benefit from LVR and may be considered to have been bridged to future transplantation, a quarter of the patients derived no benefit. One early death occurred, and survivors actually had worse pulmonary function after the procedure than before it. These patients were not bridged to transplantation, certainly. In fact, realizing the low mortality for emphysema on transplant waiting lists, I would suggest that these patients who derived no benefit from LVR would have been better served by transplant as the initial procedure. Therefore the problem as usual comes down to patient selection.

Dr. Bavaria, can you identify specific parameters in these patients in whom LVR failed, which would now lead to you recommend primary transplantation rather than LVR?

I would also be interested to know whether the technique of LVR predicts a poor outcome in certain of these patients?

In our program we have adopted a slightly different attitude in terms of selection for patients who are approaching 65 years of age. Taking into account a lengthy waiting time for a donor, we generally consider that they are going to get one operation and try and make the best judgment we can as to whether it should be transplant or LVR.

We have not noticed a significant change in the number of emphysema patients on our waiting list or the number of emphysema patients that we are evaluating. I think that the change in your list may reflect the fact that other transplant programs are now up and running in your region. In addition, I am sure that your transplant experience, the cases you do and evaluate, has also changed as your program gained experience.

Dr. Mark J. Krasna (Baltimore, Md.). Have you noticed any increase in either morbidity or mortality in performing the transplant after the bilateral LVR whether by thoracostomy or sternotomy as opposed to the patient population that had no previous pulmonary operations undergoing a standard transplant for COPD?

Dr. Bavaria. I want to answer that question first. It is a little more technically difficult, but we did not have any differences in the extubation times or the results compared with regular SLT for COPD. We were, actually, pleasantly surprised by the fact that the technical lung transplant after LVR - and we do most of our LVRs with a pleurodesis at the same time-was not quite as difficult as I thought.

Dr. Patterson's questions are appropriate. I think we do have multiple factors regarding the composition of our lung transplant list and how it has become more complex, and I think those do include the fact that our center is probably the most mature center in this area and we do have patients with more complications. Also, the major decrease in pulmonary hypertension cases in most lung transplant lists has a major effect on the lung transplant composition compared with before.

Regarding the technical questions that Dr. Patterson 
alluded to, no difference exists between the video-thoracic and the median sternotomy approaches in our experience looking at the 180 LVRs that we have done. I do, however, believe that we use the scope to operate on our patients with A-1 disease, and maybe that might have not been the right method.

To address the other question you asked about selec- tion, I believe we will get better results with LVR if we stick, especially in these low $\mathrm{FEV}_{1}$ patients, to classic disease. I do not think patients with A-1 disease did well in our group nor did patients with atypical V/Q scan changes. But if you stick with the apical disease, classic disease with low flows to each of the upper apical thirds, they did pretty well.

\section{ON THE MOVE?}

Don't miss a single issue of the journal! To ensure prompt service when you change your address, please photocopy and complete the form below.

Please send your change of address notification at least six weeks before your move to ensure continued service. We regret we cannot guarantee replacement of issues missed due to late notification.

\section{JOURNAL TITLE:}

Fill in the title of the journal here.

\section{OLD ADDRESS:}

Affix the address label from a recent issue of the journal here.

\section{NEW ADDRESS:}

Clearly print your new address here.

Name

Address

City/State/ZIP
COPY AND MAIL THIS FORM TO:

Periodical Subscription Services

Mosby, Inc.

11830 Westline Industrial Dr.

St. Louis, MO 63146-3318
OR FAX TO:

314-432-1158

N/ Mosby
OR PHONE:

1-800-453-4351

Outside the U.S., call

314-453-4351 